\title{
Mycoplasma genitalium Infection in Adults Reporting Sexual Contact with Infected Partners, Australia, 2008-2016
}

\author{
Josephine B. Slifirski, Lenka A. Vodstrcil, Christopher K. Fairley, Jason J. Ong, \\ Eric P.F. Chow, Marcus Y. Chen, Timothy R.H. Read, ${ }^{1}$ Catriona S. Bradshaw ${ }^{1}$
}

\begin{abstract}
Data on the likelihood of Mycoplasma genitalium infection in sexual contacts, particularly for men who have sex with men (MSM), are needed to form an evidence base for guidelines. We conducted a cross-sectional analysis of patients attending a sexual health clinic in Melbourne, Victoria, Australia, during 2008-2016. We calculated the proportion of contacts with $M$. genitalium infection and determined factors associated with infection. Among those patients reporting sexual contact with an $M$. genitalium-infected person, $48.2 \%$ of women, $31.0 \%$ of heterosexual men, and $41.7 \%$ of MSM were infected. Among heterosexual contacts, women were twice as likely to be infected; among MSM, rectal infection was more common than urethral infection; and among persons in heterosexual partnerships, concordance of infection was high. High positivity among female and MSM contacts and high concordance within heterosexual partnerships provide some justification for presumptive treatment; however, clinicians should consider antimicrobial drug resistance and toxicity of quinolones.
\end{abstract}

\begin{abstract}
$M$ ycoplasma genitalium is an established sexually transmitted pathogen that causes nongonococcal urethritis, and recent evidence indicates that it increases the risk for cervicitis, pelvic inflammatory disease, preterm delivery, and spontaneous abortion $(1,2)$. The estimated prevalence of $M$. genitalium infection is $1 \%-3 \%$ in men and women, according to community-based studies from the United Kingdom, United States, Australia, and Scandinavia (3-7). Early diagnosis and effective treatment are therefore important in preventing sequelae and ongoing transmission, particularly the transmission of drug-resistant strains to sex partners.
\end{abstract}

Author affiliations: Monash University, Melbourne, Victoria, Australia (J.B. Slifirski, L.A. Vodstrcil, C.K. Fairley, J.J. Ong, E.P.F. Chow, M.Y. Chen, T.R.H. Read, C.S. Bradshaw); Melbourne Sexual Health Centre, Alfred Health, Melbourne (L.A. Vodstrcil, C.K. Fairley, J.J. Ong, E.P.F. Chow, M.Y. Chen, T.R.H. Read, C.S. Bradshaw)

DOI: https://doi.org/10.3201/eid2311.170998
Published data are limited regarding the likelihood of transmission of $M$. genitalium and the proportion of persons who are likely to be infected after contact with an infected sex partner. Several small studies, with the number of participants ranging from 8 to 88 , have examined the proportion of persons infected when their partner has a confirmed $M$. genitalium infection, with results indicating a range of $20.6 \%-66.7 \%(8-14)$. However, the CIs are broad, and greater precision would provide a more accurate evidence base for partner-notification guidelines and clinical practice. To our knowledge, no published estimates of the likelihood of $M$. genitalium infection in contacts of infected men who have sex with men (MSM) are available. Studies of $M$. genitalium in MSM attending clinics report rectal infection prevalence of $1 \%-5 \%$ in predominantly asymptomatic men, whereas a recent study of MSM in Australia with proctitis found $8 \%$ of HIV-negative MSM and $20 \%$ of HIV-positive MSM had rectal M. genitalium infection (15-19).

Treatment guidelines are inconsistent about the need for presumptive treatment of sexual contacts of M. genitalium-infected patients; guidelines in the United States and United Kingdom do not recommend presumptive treatment, whereas guidelines in Australia do (20-22). Potential disadvantages of presumptive treatment include cost, unnecessary use of antimicrobial drugs, and risk for adverse effects, particularly from fluoroquinolones used for macrolide-resistant M. genitalium. The potential advantages are that early treatment might prevent reinfection of the index patient or transmission to others and prevent sequelae. The higher the likelihood of infection in a contact of a person with confirmed infection, the stronger the argument for presumptive treatment. Presumptive treatment for chlamydial infection, a sexually transmitted infection with similar characteristics to $M$. genitalium infection, is recommended based on prevalence estimates of 36\%-68\% among contacts of sex partners with confirmed chlamydial infection (23-26).

${ }^{1}$ These authors are joint senior authors for this article. 
We performed a retrospective analysis of clinical records of patients attending a large urban sexual health service in Melbourne, Victoria, Australia, who reported sexual contact with a partner with diagnosed $M$. genitalium infection. We aimed to determine the proportion of cases with $M$. genitalium and the factors associated with infection in women, heterosexual men, and MSM.

\section{Methods}

We conducted our study at the Melbourne Sexual Health Centre, the largest public STI clinic in Victoria, Australia. Starting August 2008, the clinic began treating sexual contacts of $M$. genitalium-infected patients and recording these cases in the clinic database. We defined a contact as someone who reported anal or vaginal sex with or without condoms with a person reporting a recent diagnosis of $M$. genitalium infection. Persons reporting only oral sex did not meet our definition of a contact. Persons were included at first report of being a contact, and repeat presentations were excluded. MSM were defined as men reporting any sex with men within the preceding 12 months.

We tested contacts by using an in-house real-time PCR assay targeting the 16s rRNA gene (27). Men were predominantly tested by using a first-pass urine sample, rarely with a urethral swab, and with an anorectal swab if anal sex was reported. Women were tested using a high vaginal swab or cervical swab, but a first-pass urine sample was used if patients preferred, and an anorectal swab was taken if anal sex was reported. We did not test for pharyngeal $M$. genitalium in men or women because of the absence of published evidence for infection at this anatomic site $(15,28)$.

We recorded all sexual contacts of the $M$. genitaliuminfected patients who attended the clinic during August 2008-July 2016 in the clinic database. We extracted demographic, behavioral, laboratory, and clinical data from the clinic's electronic medical records, including number and sex of sex partners, sexual practices within the preceding 3 months, whether these partners were considered casual or regular partners, and consistency of condom use. Data were routinely obtained by clinicians and computer-assisted self-interview. Signs and symptoms among men reporting sexual contact with an infected person were urethral discharge, irritation, dysuria, rectal pain, and bleeding. Signs and symptoms among women reporting sexual contact with an infected person were abnormal vaginal discharge, dysuria, abnormal bleeding, and lower abdominal pain.

We performed statistical analyses by using Stata version 12 (StataCorp LLP, College Station, TX, USA). We calculated the proportion of contacts infected with M. genitalium, including 95\% CIs, for 3 groups: women, heterosexual men, and MSM. We examined factors associated with infection for 2 groups: 1) heterosexual men and women, and 2) MSM. We conducted univariate logistic regression for each group by using demographic and behavioral characteristics as independent variables and detection of $M$. genitalium as the dependent variable. We treated age as a binary variable, with a cutoff at 27 years for all groups. We also treated the number of sex partners as a binary variable, with a cutoff at 1 for all groups. We used the $\chi^{2}$ or Fisher exact test, where appropriate, to assess the statistical significance of these associations. We calculated crude odds ratios (ORs) with 95\% CIs, entered variables with $\mathrm{p}$ values $<0.10$ in the univariate analysis in the multivariate analysis by using forward stepwise logistic regression, and calculated adjusted ORs (aORs) with 95\% CIs. In multivariate analyses, we omitted the binary variable for number of partners because of collinearity with the variable indicating whether the notifying partner was a regular or casual partner. Because some MSM had urine tests, others had rectal swabs, and some had both, we entered each test, rather than each person, into a multivariate model examining risk factors for infection in MSM by using robust SEs to account for clustering around persons.

In a subset of contacts, we were able to identify the referring partner in the clinic's electronic medical record system. If this partner's M. genitalium infection was diagnosed at the clinic within 40 days of the contact's presentation, we included the contact in a further analysis of sexual partnerships (dyads).

\section{Results}

During the study period, a total of 441 presentations to the clinic were made by patients reporting sexual contact with a person with $M$. genitalium infection (Figure). We excluded repeat presentations by the same person $(n=25)$, those missing laboratory test results $(n=16)$, those missing $>50 \%$ of the queried behavioral data $(\mathrm{n}=1)$, and those not meeting our definition of a contact $(n=22)$. These exclusions left 377 (85.5\%) persons (139 women, 126 heterosexual men, and $112 \mathrm{MSM}$ ) for analysis.

\section{Baseline Characteristics of Study Population}

We summarized baseline characteristics of the study population (Table 1). The median age of 139 female contacts was 26 years (interquartile range [IQR] 22-32 years). A total of $132(95.0 \%)$ women were heterosexual, whereas $7(5.0 \%)$ reported sex with men and women. The median age among 126 heterosexual male contacts of M. genitalium-infected patients was 28 years (IQR 24-35 years). The median age among $112 \mathrm{MSM}$ contacts of M. genitalium-infected patients was 29 years (IQR 25-36 years). Most contacts in all 3 groups reported that their notifying partner was their regular partner, and most reported $<100 \%$ condom use during the preceding 3 months. 


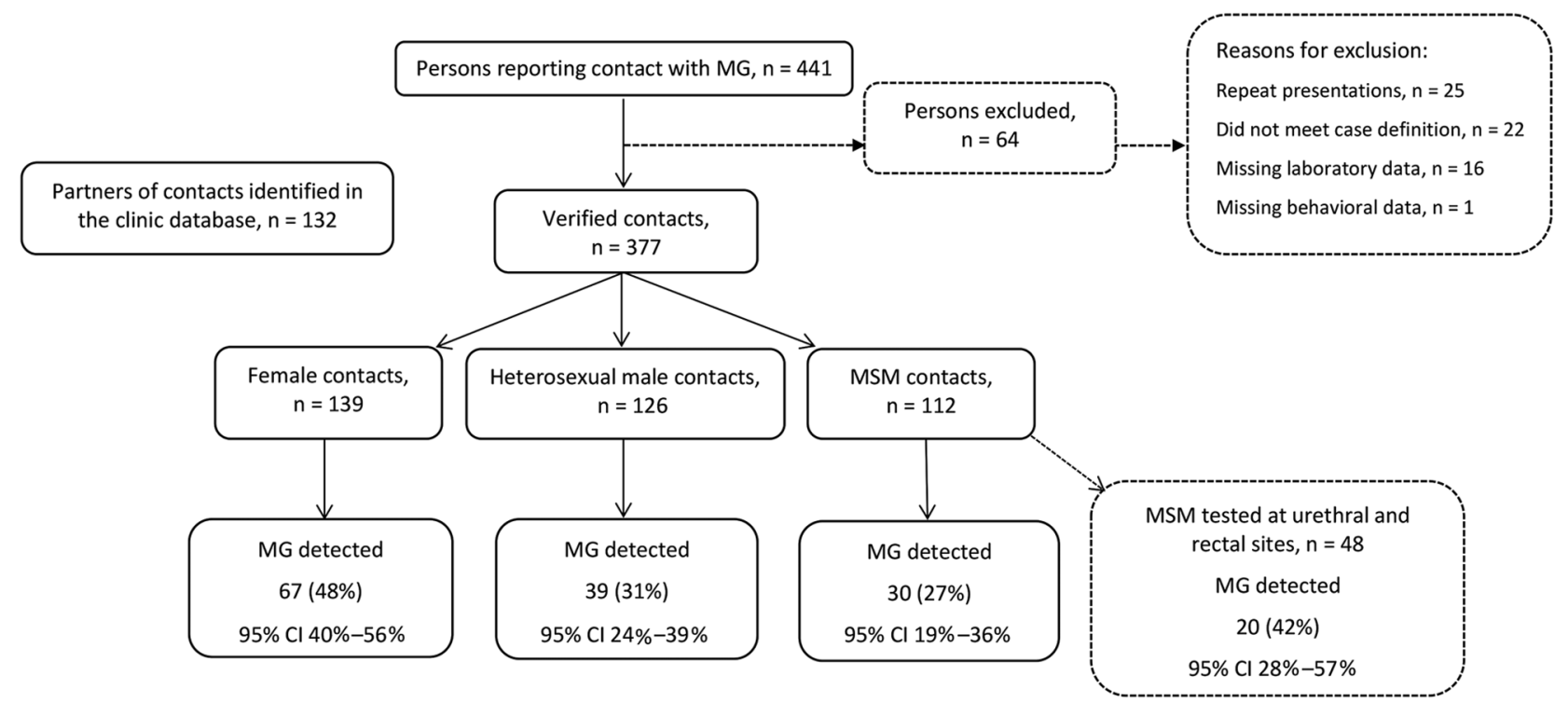

Figure. Flowchart for 441 persons examined at Melbourne Sexual Health Centre who reported sexual contact with a Mycoplasma genitalium-infected partner, Melbourne, Victoria, Australia, August 2008-July 2016. Dashed lines indicate persons excluded for analysis or subanalysis. MG, Mycoplasma genitalium; MSM, men who have sex with men.

\section{M. genitalium Infection in Sexual Contacts}

\section{Heterosexual Women and Men}

Because $M$. genitalium positivity did not significantly differ between cervical or high vaginal swabs or first-pass urine samples among women $(50.0 \%$ vs. $46.1 \%$; $\mathrm{p}=0.643)$, we combined these samples for our analysis. The overall proportion of female contacts in whom $M$. genitalium was detected was $48.2 \%$ (95\% CI 39.7\%-56.8\%). The proportion of heterosexual male contacts in whom urethral M. genitalium was detected was 31.0\% (95\% CI 23.0\%-39.8\%), which was significantly lower than the proportion of female contacts infected $(\mathrm{p}=0.004)$.

\section{MSM}

The proportion of MSM contacts in whom M. genitalium was detected overall was 26.8\% (95\% CI 18.9\%$36.0 \%)$. However, only 48 (42.9\%) MSM were tested at both anatomic sites; $48(42.9 \%)$ were tested only at the urethra, and $16(14.3 \%)$ were tested only at the rectum. Of the 48 MSM contacts tested only at the urethra, 3 had M. genitalium detected $(6.3 \%$, 95\% CI 1.3\%-17.2\%). In contrast, of the $16 \mathrm{MSM}$ contacts tested only at the rectum, 7 had $M$. genitalium detected $(43.8 \%$, 95\% CI $19.8 \%-70.1 \%$ ). Of the 48 MSM contacts tested at both anatomic sites, 20 had $M$. genitalium detected $(41.7 \%$, $95 \%$ CI $27.6 \%-56.8 \%$ ), with most (17/20) of these infections being rectal infections. Overall, 8 of 96 urethral sites tested for $M$. genitalium were positive $(8.3 \%, 95 \%$ CI $4.3 \%-15.6 \%$ ), compared with 24 of 59 rectal sites (40.7\%, 95\% CI 29.1\%-53.4\%).
Factors Associated with Having M. genitalium Infection

\section{Heterosexual Female and Male Contacts}

We examined potential predictors of $M$. genitalium infection among heterosexual women and men (Table 2). Factors associated with being infected with $M$. genitalium on univariate analysis included female sex $(p=0.004)$, having a regular partner as the notifying partner $(p=0.013)$, and having $\geq 2$ sex partners in the preceding 3 months ( $p=$ 0.024 ). Factors that were significantly associated with being infected were included in a multivariate analysis; number of sex partners was not included because it was highly correlated with having a regular partner as the notifying partner, and condom use with the notifying partner was included given the protective effect of condoms against STI acquisition. Heterosexual contacts were more likely to be infected with $M$. genitalium if they were women (aOR 2.18, 95\% CI 1.28-3.71) and the notifying partner was a regular sex partner (aOR 2.13, 95\% CI 1.09-4.14). Contacts reporting $<100 \%$ condom use with their notifying partner were 2.72 times more likely to have $M$. genitalium diagnosed, although this difference was not statistically significant ( $p$ $=0.066$ ). The presence of any urethral discharge, irritation, or dysuria was associated with detection of $M$. genitalium in heterosexual men (OR 3.26, 95\% CI 1.24-8.58). Symptoms were not associated with detection in women or in the combined (male and female) heterosexual model (Table 2).

\section{MSM Contacts}

Because most MSM were tested only at the urethra or the rectum, we based our analysis on the anatomic sites tested 
Table 1. Baseline characteristics of 377 persons seen at Melbourne Sexual Health Centre who reported sexual contact with an Mycoplasma genitalium-infected partner, Melbourne, Victoria, Australia, August 2008-July 2016*

\begin{tabular}{lccc}
\hline Characteristic & Women, $\mathrm{n}=139$ & Heterosexual men, $\mathrm{n}=126$ & $\mathrm{MSM}, \mathrm{n}=112$ \\
\hline Age, $\mathrm{y}$, median (IQR) & $26(22-32)$ & $28(24-35)$ & $29(25-36)$ \\
\hline No. sex partners in preceding 3 mot & & & \\
$\quad 1$ & $74(53.6)$ & $52(41.9)$ & $37(35.6)$ \\
$\quad \geq 2$ & $64(46.4)$ & $72(58.1)$ & $67(64.4)$ \\
\hline $\begin{array}{l}\text { Condom use with all sex partners in preceding 3 mo } \\
\quad 100 \%\end{array}$ & $11(8.0)$ & $6(4.9)$ & $15(14.4)$ \\
$\quad<100 \%$ & $126(92.0)$ & $117(95.1)$ & $89(85.6)$ \\
\hline Nature of relationship with the notifying partner & & & \\
$\quad$ Casual & $28(20.9)$ & $36(29.0)$ & $38(36.2)$ \\
$\quad$ Regular & $106(79.1)$ & $88(71.0)$ & $67(63.8)$ \\
\hline Condom use with the notifying partner in preceding 3 mo & $15(11.6)$ & $6(4.9)$ & $15(14.9)$ \\
$\quad 100 \%$ & $114(88.4)$ & $117(95.1)$ & $86(85.1)$ \\
$\quad<100 \%$ & &
\end{tabular}

*Values are no. (\%) unless otherwise specified. IQR, interquartile range; MSM, men who have sex with men.

†Number of sex partners does not include female sex partners for female contacts or MSM contacts.

for M. genitalium rather than persons. By including each urethral $(\mathrm{n}=96)$ and rectal $(\mathrm{n}=59)$ test as individual observations within the dataset, we observed that 112 MSM contacts had 155 separate tests for M. genitalium. Factors that were significantly associated with infection on univariate analysis (or that were of borderline significance) included reporting having 1 sex partner in the preceding 3 months $(p=0.071)$, reporting $<100 \%$ condom use with the notifying partner in the preceding 3 months $(p=0.061)$, and being tested at the rectal site $(p<0.001)$ (Table 3$)$. Including these 3 factors in a multivariate analysis, MSM contacts had an 8-fold increase in probability of $M$. genitalium infection if they were tested at the rectum instead of the urethra (aOR 8.39, 95\% CI 3.14 22.42). In separate univariate analyses, restricted to persons tested at the relevant site, symptoms were not associated with detection of M. genitalium (Table 3).

\section{M. genitalium Infection in Sexual Partnerships (Dyads)}

Of 377 contacts, 132 (35\%) reported having been notified by a partner who could be identified in the clinic's electronic medical record system. A total of 120 (91\%) partnerships fulfilled the inclusion criteria for further analysis. In 86 heterosexual dyads, the median time between the contact and their partner being tested for M. genitalium was 8 days (IQR 6-16 days); in 34 MSM dyads, it was 7 days (IQR 4-11 days). Forty of 86 heterosexual dyads were concordant for $M$. genitalium infection $(46.5 \%, 95 \%$ CI $36.4 \%-57.0 \%$ ). Nine of $34 \mathrm{MSM}$ dyads were concordant for infection $(26.5 \%, 95 \%$ CI $14.6 \%-43.1 \%)$; however, few MSM dyads were tested for M. genitalium at both urethral and rectal sites. Of $34 \mathrm{MSM}$ notifying partners that were identified, $29(85.3 \%)$ had a history of urethral $M$. genitalium infection and $5(14.7 \%)$ had a history of rectal M. genitalium infection.

\section{Discussion}

In this study, a high proportion of persons reporting contact with an M. genitalium-infected partner were infected, including $48 \%$ of women, $31 \%$ of heterosexual men, and $42 \%$ of MSM tested at both the rectum and urethra. The sample size for this study exceeds the combined total of sample sizes in previously published studies, adding precision to estimates of the probability of infection and transmissibility of $M$. genitalium between sex partners $(8-14)$. These findings will inform guidelines for the management of sexual contacts of $M$. genitalium-infected patients and provide an evidence base for informed discussion between clinicians and their patients regarding the appropriateness of presumptive treatment for contacts of infected patients or recommending testing and return for treatment.

In this study, among heterosexual contacts, women were twice as likely as men to be infected with M. genitalium, after adjusting for condom use and nature of relationship. This finding could be attributable to the female genital tract's greater susceptibility to STIs, with the larger surface area of the cervico-vaginal mucosa compared with the urethral mucosa (29), and female sex hormones thought to enhance susceptibility to STIs (30). Heterosexual contacts notified by a regular partner were twice as likely to be infected, suggesting that multiple sexual acts or events of exposure might increase risk for acquisition of M. genitalium. Less than $100 \%$ condom use for penile-vaginal sex with a regular partner appeared to double the risk for $M$. genitalium infection among heterosexual contacts, and although this increased risk was not significant $(p=0.07)$, it does suggest that condoms provide protection against $M$. genitalium infection, as has been shown for other bacterial STIs. Concordance for $M$. genitalium infection in heterosexual dyads in which both partners were tested at our service was $47 \%$, reflecting the high risk for concurrent infection in heterosexual partnerships. Overall, the prevalence of M. genitalium infection in heterosexual men and women was within the range reported for chlamydial infection in published studies (23-26).

The prevalence of $M$. genitalium that was observed among contacts in this study is substantially higher than the 
Table 2. Potential predictors of Mycoplasma genitalium infection among heterosexual men and women seen at Melbourne Sexual Health Centre who reported sexual contact with an M. genitalium-infected partner, Melbourne, Victoria, Australia, August 2008-July $2016^{*}$

\begin{tabular}{|c|c|c|c|c|c|c|c|}
\hline Characteristic & No. & $\begin{array}{l}\text { Infected, } \\
\text { no. }(\%)\end{array}$ & $\begin{array}{l}\text { Not infected, } \\
\text { no. }(\%)\end{array}$ & $\begin{array}{l}\text { Unadjusted OR } \\
(95 \% \mathrm{Cl})\end{array}$ & $p$ value & aOR† $(95 \% \mathrm{Cl})$ & $p$ value \\
\hline Total & 265 & & & & & & \\
\hline \multicolumn{8}{|c|}{ Age of sex partner, $y \ddagger$} \\
\hline$\geq 27$ & 141 & $53(37.6)$ & $88(62.4)$ & 1.0 & & & \\
\hline$<27$ & 124 & $53(42.7)$ & $71(57.3)$ & $0.81(0.49-1.32)$ & 0.393 & - & - \\
\hline \multicolumn{8}{|l|}{ Sex } \\
\hline M & 126 & $39(31.0)$ & $87(69.0)$ & 1.0 & & 1.0 & \\
\hline $\mathrm{F}$ & 139 & $67(48.2)$ & $72(51.8)$ & $2.08(1.25-3.43)$ & 0.004 & $2.18(1.28-3.71)$ & 0.004 \\
\hline \multicolumn{8}{|c|}{ No. of sex partners in preceding $3 \mathrm{mo}$} \\
\hline 1 & 126 & $59(46.8)$ & $67(53.2)$ & 1.0 & & & \\
\hline$\geq 2$ & 136 & $45(33.1)$ & $91(66.9)$ & $0.56(0.34-0.93)$ & 0.024 & - & - \\
\hline \multicolumn{8}{|c|}{ Nature of relationship with the notifying partner } \\
\hline Casual & 64 & $17(26.6)$ & $47(73.4)$ & 1.0 & & 1.0 & \\
\hline Regular & 194 & $86(44.3)$ & $108(55.7)$ & $2.20(1.18-4.10)$ & 0.013 & $2.13(1.09-4.14)$ & 0.026 \\
\hline \multicolumn{8}{|c|}{ Condom use with notifying partner in preceding $3 \mathrm{mo}$} \\
\hline $100 \%$ & 21 & $5(23.8)$ & $16(76.2)$ & 1.0 & & 1.0 & \\
\hline$<100 \%$ & 231 & $97(42.0)$ & $134(58.0)$ & $2.32(0.13-1.27)$ & 0.113 & $2.72(0.93-7.91)$ & 0.066 \\
\hline \multicolumn{8}{|c|}{ Symptoms in men§ } \\
\hline No & 99 & $25(25.3)$ & $74(74.7)$ & 1.0 & & & \\
\hline Yes & 21 & $11(52.4)$ & $10(47.6)$ & $3.26(1.24-8.58)$ & 0.017 & - & - \\
\hline \multicolumn{8}{|c|}{ Symptoms in womenף } \\
\hline No & 93 & $45(48.4)$ & $48(51.6)$ & 1.0 & & - & - \\
\hline Yes & 24 & $14(58.3)$ & $10(41.7)$ & $1.49(0.60-3.70)$ & 0.387 & & \\
\hline \multicolumn{8}{|c|}{$\begin{array}{l}\text { *Bold text indicates a statistically significant association ( } p<0.05) \text {. Up to } 7 \% \text { of participants have missing data for some variables. aOR, adjusted odds } \\
\text { ratio; MSM, men who have sex with men; OR, odds ratio. } \\
\text { †Adjusted for sex, nature of relationship with notifying partner, and reported condom use }(100 \% \text { vs. }<100 \%) \text {. } \\
\text { fThe median age across all female, heterosexual male, and MSM contacts was } 27 \text { years. } \\
\text { §Discharge, dysuria, or urethral irritation; } 6 \text { men with urethral chlamydia excluded. In the combined heterosexual population symptoms were not } \\
\text { significantly associated with infection and were not included in the multivariate model. } \\
\text { TVaginal discharge, dysuria, abnormal bleeding, or lower abdominal pain; } 22 \text { women with candidiasis, bacterial vaginosis, chlamydia, or urinary tract } \\
\text { infections excluded. }\end{array}$} \\
\hline
\end{tabular}

prevalence reported in comparable study populations in Melbourne. Reported prevalence estimates from these studies were $2.4 \%$ (95\% CI $1.5 \%-3.3 \%$ ) in young women attending clinics, including the site of this study (4); $1.3 \%$ (95\% CI $0.3 \%-3.7 \%$ ) in urine samples from asymptomatic heterosexual men (31); and (2.1\%; 95\% CI 1.1\%-3.6\%) in rectal swabs and urine samples from asymptomatic MSM (15), all of which are much lower than the respective prevalence estimates reported in our study of $48.2 \%$ (95\% CI 39.7\%-56.8\%), 31.0\% (95\% CI 23.0\%-39.8\%), and 41.7\% (95\% CI 27.6\%-56.8\%).

MSM contacts had a similar likelihood of being infected with $M$. genitalium as women when they were tested at both the urethra and the rectum. This study highlights the importance of rectal testing for M. genitalium in MSM. Urethral positivity was only $8 \%$ in MSM, compared with $31 \%$ in heterosexual men. However, overall rectal positivity was high at $38 \%$, and when MSM were tested at both urethral and rectal sites, $42 \%$ were positive for $M$. genitalium, and most of these had rectal infections. The clinic records do not indicate why some men were not tested at both sites. The higher rate of rectal infection compared with urethral infection is consistent with studies of chlamydial infection among MSM but is also likely to be influenced by the notifying partner's reason for seeking care. When this factor was examined among MSM dyads, 29 of 34 MSM notifying partners sought care for urethral infections, suggesting that urethral infections might be more likely than rectal infections to cause symptoms.

Our study has several limitations. The study is retrospective and relies on self-report of exposure to infection without laboratory confirmation. As such, the data reflect the prevalence of infection only among those persons who seek care reporting exposure to $M$. genitalium rather than among all of those exposed. We have no information on contacts of infected patients who did not attend the clinic, and these persons are likely to be systematically different from those who did seek out testing and treatment. These findings might also not be generalizable to non-STI clinic populations or to other populations with a different background prevalence of M. genitalium infection. Although we considered the notifying partner the index patient for analytical purposes, we cannot ascertain the transmission direction between sex partners or whether transmission occurred through a third person. Sexual behavioral data were self-reported and hence subject to recall bias. The most notable limitation was the lack of dual-site testing for MSM contacts, which limited our ability to report precise estimates of infection among MSM and to examine concordance in MSM dyads.

Presumptive treatment of sexual contacts reduces the risk for reinfection and is recommended for STI syndromes 
Table 3. Factors associated with detection of Mycoplasma genitalium infection among MSM examined at Melbourne Sexual Health Centre who reported sexual contact with an M. genitalium-infected partner, Melbourne, Victoria, Australia, August 2008-July 2016*

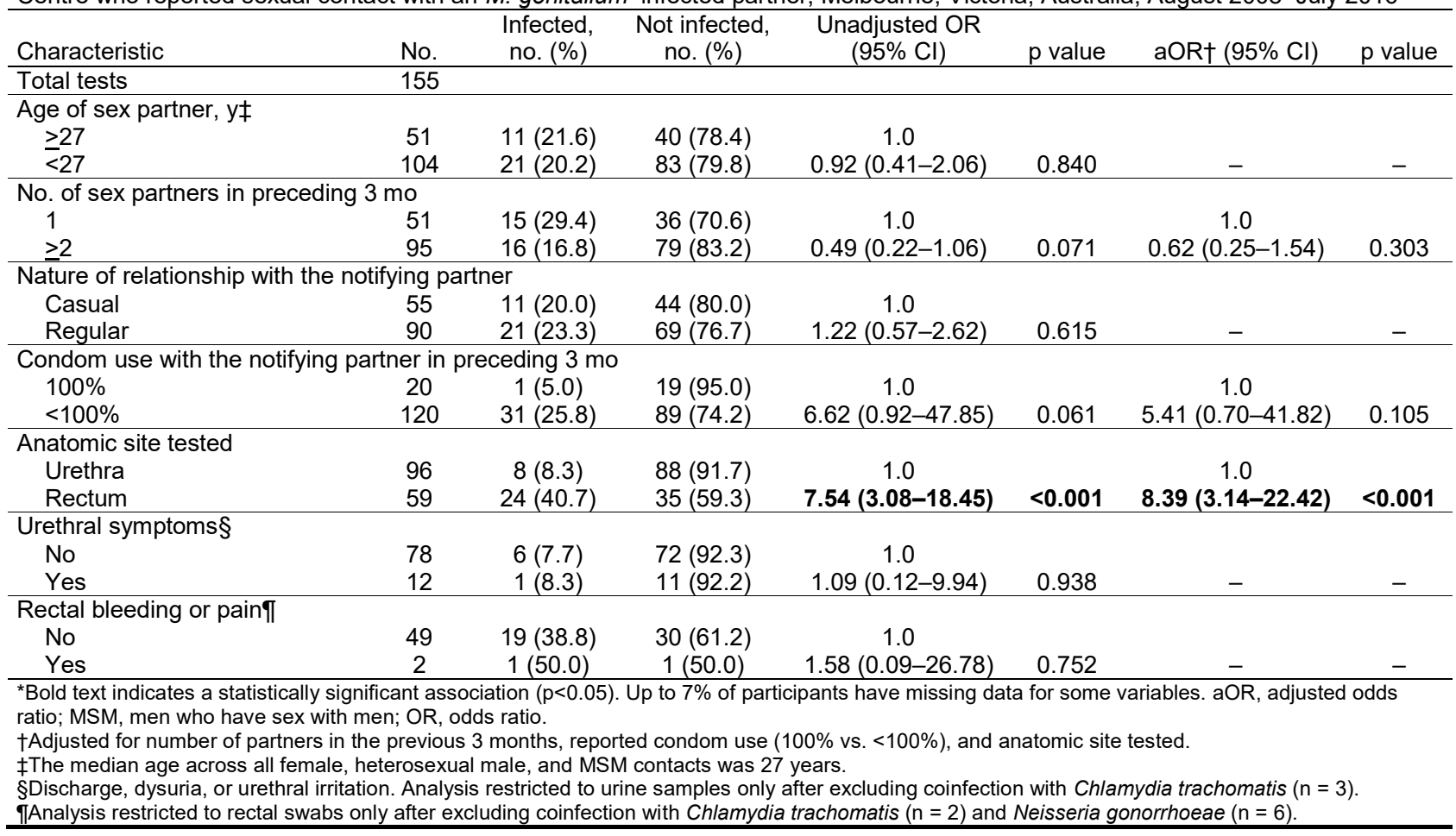

such as nongonococcal urethritis (20). In the contacts of $M$. genitalium-infected persons in this study, presumptive treatment would have treated 1 infection for every 2-3 treatments. However, the decision to recommend presumptive treatment must also take into account potential harms and benefits to the contact and their sex partners. Although heterosexual men had a slightly lower prevalence of positivity, presumptive treatment might be more important in reducing the risk for serious sequelae, such as pelvic inflammatory disease, in female partners.

The alternate approach of treating contacts only after confirmation of $M$. genitalium infection represents better stewardship of antimicrobial drugs but relies on access to sensitive testing practices and a high rate of return of patients to be effective. An important consideration before presumptively treating contacts for $M$. genitalium infection is the increasing prevalence of macrolide resistance, which is $>40 \%$ in Europe, Japan, and the United States and $>75 \%$ among MSM in Australia (32-35). Furthermore, macrolide resistance is selected in $12 \%-18 \%$ of seemingly susceptible infections after treatment with $1 \mathrm{~g}$ azithromycin and extended azithromycin regimens (35). Presumptive use of macrolides for $M$. genitalium-infected contacts might therefore not only be ineffective in those patients with detectable resistance but also contribute to development and spread of resistance, particularly in asymptomatic contacts who believe they have been effectively treated. The only recommended treatments for macrolide-resistant M. genitalium are fourth-generation fluoroquinolones, which are expensive and can cause tendinopathy, neuropathy, and adverse central nervous system effects, which are major considerations for determining their use in persons who do not have confirmed infection. Overall, a prudent approach entails managing sexual contacts according to the informed preferences of the person and, if known, the resistance status of the notifying partner. The results of our study provide an evidence base for informed discussions between clinicians and patients at risk for infection and can inform international treatment and partner-notification guidelines.

A. Afrizal provided technical assistance by extracting the participants' unique identification codes for this study from the Melbourne Sexual Health Centre patient database.

This work did not directly receive any financial support; however, 3 coauthors were supported by the Australian National Health and Medical Research Council: Early Career Fellowship no. 1091536 to T.R.H.R., Early Career Fellowship no. 1104781 to J.J.O., and Early Career Fellowship no. 1091226 to E.P.F.C.

Ms. Slifirski earned a bachelor's degree with honors in biomedical science from the Central Clinical School at Monash University. She undertook this research project during her honors year and has since enrolled in a postgraduate bachelor of medicine degree at Deakin University. 


\section{References}

1. Taylor-Robinson D, Jensen JS. Mycoplasma genitalium: from Chrysalis to multicolored butterfly. Clin Microbiol Rev 2011;24:498-514. http://dx.doi.org/10.1128/CMR.00006-11

2. Lis R, Rowhani-Rahbar A, Manhart LE. Mycoplasma genitalium infection and female reproductive tract disease: a meta-analysis. Clin Infect Dis. 2015;61:418-26. http://dx.doi.org/10.1093/cid/civ312

3. Sonnenberg P, Ison CA, Clifton S, Field N, Tanton C, Soldan K, et al. Epidemiology of Mycoplasma genitalium in British men and women aged 16-44 years: evidence from the third National Survey of Sexual Attitudes and Lifestyles (Natsal-3). Int J Epidemiol. 2015;44:1982-94. http://dx.doi.org/10.1093/ije/dyv194

4. Walker J, Fairley CK, Bradshaw CS, Tabrizi SN, Chen MY, Twin J, et al. The difference in determinants of Chlamydia trachomatis and Mycoplasma genitalium in a sample of young Australian women. BMC Infect Dis. 2011;11:35. http://dx.doi.org/10.1186/ 1471-2334-11-35

5. Andersen B, Sokolowski I, Østergaard L, Kjølseth Møller J, Olesen F, Jensen JS. Mycoplasma genitalium: prevalence and behavioural risk factors in the general population. Sex Transm Infect. 2007;83:237-41. http://dx.doi.org/10.1136/sti.2006.022970

6. Oakeshott P, Aghaizu A, Hay P, Reid F, Kerry S, Atherton H, et al. Is Mycoplasma genitalium in women the "new chlamydia?" A community-based prospective cohort study. Clin Infect Dis. 2010;51:1160-6. http://dx.doi.org/10.1086/656739

7. Manhart LE, Holmes KK, Hughes JP, Houston LS, Totten PA. Mycoplasma genitalium among young adults in the United States: an emerging sexually transmitted infection. Am J Public Health. 2007;97:1118-25. http://dx.doi.org/10.2105/AJPH.2005.074062

8. Anagrius C, Loré B, Jensen JS. Mycoplasma genitalium: prevalence, clinical significance, and transmission. Sex Transm Infect. 2005;81:458-62. http://dx.doi.org/10.1136/sti.2004.012062

9. Falk L, Fredlund H, Jensen JS. Signs and symptoms of urethritis and cervicitis among women with or without Mycoplasma genitalium or Chlamydia trachomatis infection. Sex Transm Infect. 2005;81:73-8. http://dx.doi.org/10.1136/sti.2004.010439

10. Falk L, Fredlund H, Jensen JS. Symptomatic urethritis is more prevalent in men infected with Mycoplasma genitalium than with Chlamydia trachomatis. Sex Transm Infect. 2004;80:289-93. http://dx.doi.org/10.1136/sti.2003.006817

11. Keane FE, Thomas BJ, Gilroy CB, Renton A, Taylor-Robinson D. The association of Chlamydia trachomatis and Mycoplasma genitalium with non-gonococcal urethritis: observations on heterosexual men and their female partners. Int J STD AIDS. 2000;11:435-9. http://dx.doi.org/10.1258/0956462001916209

12. Thurman AR, Musatovova O, Perdue S, Shain RN, Baseman JG, Baseman JB. Mycoplasma genitalium symptoms, concordance and treatment in high-risk sexual dyads. Int J STD AIDS. 2010;21:17783. http://dx.doi.org/10.1258/ijsa.2009.008485

13. Tosh AK, Van Der Pol B, Fortenberry JD, Williams JA, Katz BP, Batteiger BE, et al. Mycoplasma genitalium among adolescent women and their partners. J Adolesc Health. 2007;40:412-7. http://dx.doi.org/10.1016/j.jadohealth.2006.12.005

14. Wikström A, Jensen JS. Mycoplasma genitalium: a common cause of persistent urethritis among men treated with doxycycline. Sex Transm Infect. 2006;82:276-9. http://dx.doi.org/10.1136/ sti.2005.018598

15. Bradshaw CS, Fairley CK, Lister NA, Chen SJ, Garland SM, Tabrizi SN. Mycoplasma genitalium in men who have sex with men at male-only saunas. Sex Transm Infect. 2009;85:432-5. http://dx.doi.org/10.1136/sti.2008.035535

16. Francis SC, Kent CK, Klausner JD, Rauch L, Kohn R, Hardick A, et al. Prevalence of rectal Trichomonas vaginalis and Mycoplasma genitalium in male patients at the San Francisco STD clinic, 2005-2006. Sex Transm Dis. 2008;35:797-800. http://dx.doi.org/10.1097/OLQ.0b013e318177ec39
17. Bissessor M, Tabrizi SN, Bradshaw CS, Fairley CK, Hocking JS, Garland SM, et al. The contribution of Mycoplasma genitalium to the aetiology of sexually acquired infectious proctitis in men who have sex with men. Clin Microbiol Infect. 2016;22:260-5. http://dx.doi.org/10.1016/j.cmi.2015.11.016

18. Soni S, Alexander S, Verlander N, Saunders P, Richardson D, Fisher M, et al. The prevalence of urethral and rectal Mycoplasma genitalium and its associations in men who have sex with men attending a genitourinary medicine clinic. Sex Transm Infect. 2010;86:21-4. http://dx.doi.org/10.1136/sti.2009.038190

19. Zheng BJ, Yin YP, Han Y, Shi MQ, Jiang N, Xiang Z, et al. The prevalence of urethral and rectal Mycoplasma genitalium among men who have sex with men in China, a cross-sectional study. BMC Public Health. 2014;14:195. http://dx.doi.org/10.1186/ 1471-2458-14-195

20. Centers for Disease Control and Prevention. 2015 sexually transmitted diseases treatment guidelines [cited 2016 Sep 20]. http://www.cdc.gov/std/tg2015/default.htm

21. Horner P, Blee K, O’Mahony C, Muir P, Evans C, Radcliffe K; Clinical Effectiveness Group of the British Association for Sexual Health and HIV. 2015 UK national guideline on the management of non-gonococcal urethritis. Int J STD AIDS. 2016;27:85-96. http://dx.doi.org/10.1177/0956462415586675

22. Australasian Sexual Health Alliance. Mycoplasma genitalium [cited 2016 Oct 20]. http://www.sti.guidelines.org.au/ sexually-transmissible-infections/mycoplasma-genitalium

23. Huffam S, Chow EP, Fairley CK, Hocking J, Peel J, Chen M. Chlamydia infection in individuals reporting contact with sexual partners with chlamydia: a cross-sectional study of sexual health clinic attendees. Sex Transm Infect. 2015;91:434-9. http://dx.doi.org/10.1136/sextrans-2015-052068

24. Khan A, Fortenberry JD, Juliar BE, Tu W, Orr DP, Batteiger BE. The prevalence of chlamydia, gonorrhea, and trichomonas in sexual partnerships: implications for partner notification and treatment. Sex Transm Dis. 2005;32:260-4. http://dx.doi.org/ 10.1097/01.olq.0000161089.53411.cb

25. Quinn TC, Gaydos C, Shepherd M, Bobo L, Hook EW III, Viscidi R, et al. Epidemiologic and microbiologic correlates of Chlamydia trachomatis infection in sexual partnerships. JAMA. 1996;276:1737-42. http://dx.doi.org/10.1001/ jama.1996.03540210045032

26. Schembri G, Schober P. Risk factors for chlamydial infection in chlamydia contacts: a questionnaire-based study. J Fam Plann Reprod Health Care. 2011;37:10-6. http://dx.doi.org/10.1136/ jfprhc. 2010.0004

27. Twin J, Taylor N, Garland SM, Hocking JS, Walker J, Bradshaw CS, et al. Comparison of two Mycoplasma genitalium real-time PCR detection methodologies. J Clin Microbiol. 2011;49:1140-2. http://dx.doi.org/10.1128/JCM.02328-10

28. Deguchi T, Yasuda M, Yokoi S, Nakano M, Ito S, Ohkusu K, et al. Failure to detect Mycoplasma genitalium in the pharynges of female sex workers in Japan. J Infect Chemother. 2009;15:410-3. http://dx.doi.org/10.1007/s10156-009-0726-4

29. Yi TJ, Shannon B, Prodger J, McKinnon L, Kaul R. Genital immunology and HIV susceptibility in young women. Am J Reprod Immunol. 2013;69(Suppl 1):74-9. http://dx.doi.org/10.1111/ aji. 12035

30. Kaushic C, Roth KL, Anipindi V, Xiu F. Increased prevalence of sexually transmitted viral infections in women: the role of female sex hormones in regulating susceptibility and immune responses. J Reprod Immunol. 2011;88:204-9. http://dx.doi.org/10.1016/ j.jri.2010.12.004

31. Bradshaw CS, Tabrizi SN, Read TR, Garland SM, Hopkins CA, Moss LM, et al. Etiologies of nongonococcal urethritis: bacteria, viruses, and the association with orogenital exposure. J Infect Dis. 2006;193:336-45. http://dx.doi.org/10.1086/499434 
32. Dumke R, Thürmer A, Jacobs E. Emergence of Mycoplasma genitalium strains showing mutations associated with macrolide and fluoroquinolone resistance in the region Dresden, Germany. Diagn Microbiol Infect Dis. 2016;86:221-3. http://dx.doi.org/ 10.1016/j.diagmicrobio.2016.07.005

33. Gesink D, Racey CS, Seah C, Zittermann S, Mitterni L, Juzkiw J, et al. Mycoplasma genitalium in Toronto, Ont: estimates of prevalence and macrolide resistance. Can Fam Physician. 2016;62:e96-101.

34. Getman D, Jiang A, O'Donnell M, Cohen S. Mycoplasma genitalium prevalence, coinfection, and macrolide antibiotic resistance frequency in a multicenter clinical study cohort in the
United States. J Clin Microbiol. 2016;54:2278-83. http://dx.doi. org/ 10.1128/JCM.01053-16

35. Read TR, Fairley CK, Tabrizi SN, Bissessor M, Vodstrcil L, Chow EP, et al. Azithromycin 1.5g over 5 days compared to $1 \mathrm{~g}$ single dose in urethral Mycoplasma genitalium: impact on treatment outcome and resistance. Clin Infect Dis. 2017;64: 250-6. http://dx.doi.org/10.1093/cid/ciw719

Address for correspondence: Catriona S. Bradshaw, Melbourne Sexual Health Centre, 580 Swanston St, Carlton, Victoria 3053, Australia; email: catriona.bradshaw@monash.edu

\section{Global Health Security Special Issue Supplement to Emerging Infectious Diseases December 2017}

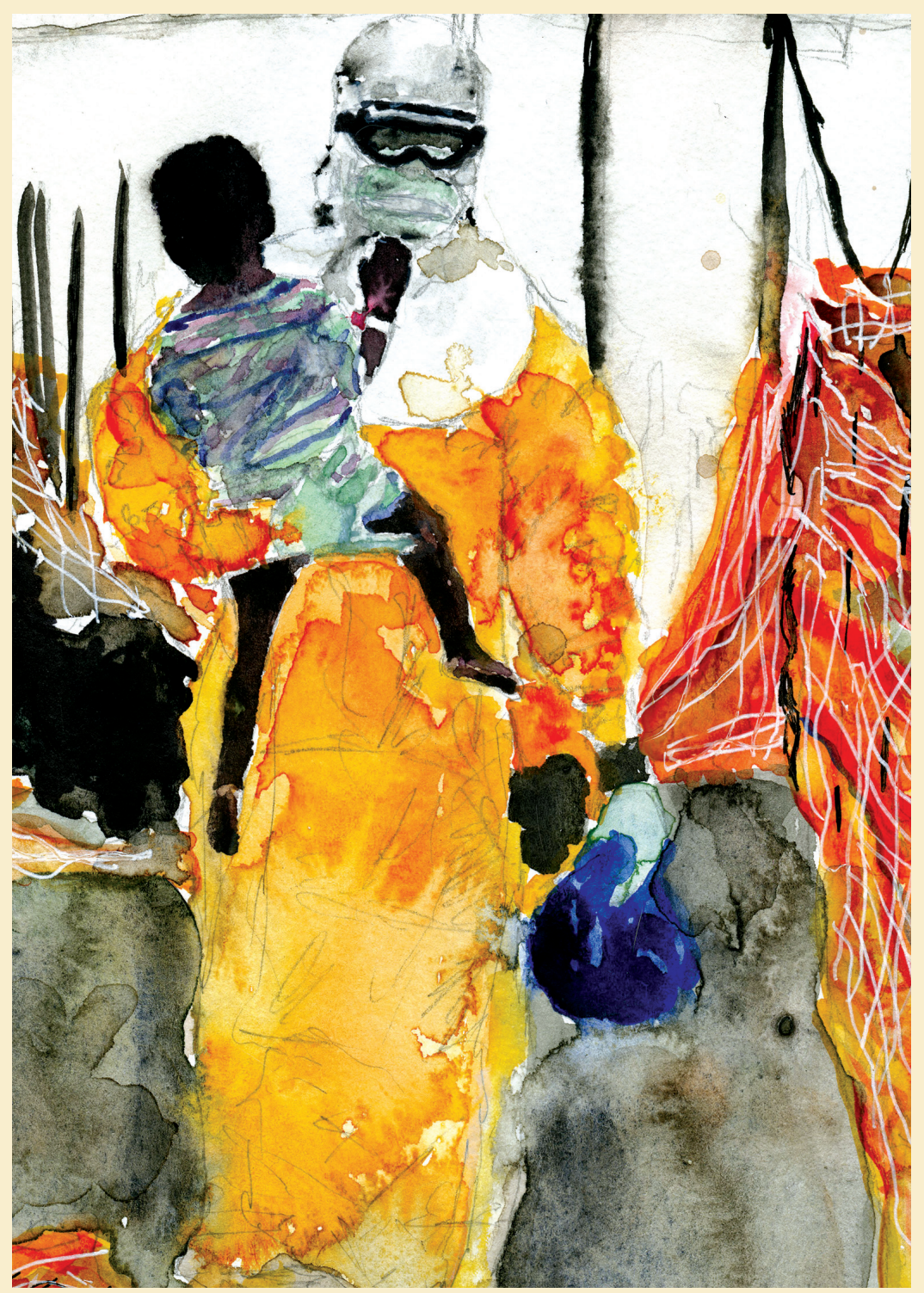

The upcoming Emerging Infectious Diseases supplement on global health security highlights how $C D C$ remains a trusted partner and leader in establishing a worldwide platform to stop infectious diseases from crossing borders and threatening the health, safety, and security of Americans.

The supplement includes contributions from experts across the globe and highlights the importance of sustained, lifesaving investment in global health security initiatives. With more than $70 \%$ of countries still underprepared to contain outbreaks, this timely series of articles illustrates work being done to close the gaps that leave us all vulnerable to dangerous and deadly epidemics.

The online release begins in September with the lead article: US Centers for Disease Control and Prevention and its Partners' Contributions to Advance Global Health Security. The print edition of this special issue will be published in December 2017. 